\title{
Lateral medullary syndrome post-chiropractic manipulation in a 25-year old female with headache
}

\author{
Matthew Kynan Burrage, Clare Therese Costello
}

\begin{abstract}
Introduction: Cervical chiropractic manipulation forthetreatmentofbackand neckpain is becoming increasingly commonplace, especially amongst younger adults. It may also give rise to serious complications, such as dissection of cervical arteries with resultant stroke syndromes. This case report reviews the literature surrounding this issue and highlights the importance of correctly diagnosing cerebrovascular pathology in young adults. Case Report: We describe a case of a 25-year-old female with delayed onset of focal neurology and lateral medullary syndrome postchiropractic cervical manipulation. Magnetic resonance angiogram and computed tomography angiogram confirm lateral medullary infarction and bilateral vertebral artery dissection. Conclusion: Currently, chiropractic manipulation and complications are a relatively topical issue and some of the potential serious complications are discussed in this case. Certain posterior circulation stroke symptoms belong to distinct clinical syndromes and it is important to be aware of these when assessing patients with possible posterior circulation ischemia. This is especially important in younger populations, where misdiagnosis as migraine may be a common pitfall. Headache and focal neurology
\end{abstract}

Matthew Kynan Burrage ${ }^{1}$, Clare Therese Costello ${ }^{2}$ Affiliations: ${ }^{1}$ MBBS, House Officer, Princess Alexandra Hospital, Brisbane, Queensland, Australia; ${ }^{2} \mathrm{MBBS}$, House Officer, Ipswich General Hospital, Brisbane, Queensland, Australia.

Corresponding Author: Matthew Kynan Burrage, Princess Alexandra Hospital, 199 Ipswich Road, Woolloongabba, Brisbane Queensland, AUSTRALIA 4102; Ph: +61 (07) 3176 2111; Email: mkburrage@gmail.com

Received: 10 December 2012

Accepted: 21 June 2013

Published: 01 April 2014 following chiropractic cervical manipulation should be managed and investigated with a high index of suspicion for vertebral artery dissection.

Keywords: Lateral medullary syndrome, Chiropractor, Vertebral dissection

\section{How to cite this article}

Burrage MK, Costello CT. Lateral medullary syndrome post-chiropractic manipulation in a 25 -year old female with headache. International Journal of Case Reports and Images 2014;5(4):295-298.

doi:10.5348/ijcri-20146o-CR-10371

\section{INTRODUCTION}

Lateral medullary syndrome, a posterior circulation stroke syndrome with a distinct set of clinical findings, is a recognized consequence of vertebral artery dissection. Cervical artery dissection (including vertebral artery dissection) is a documented complication of chiropractic cervical spinal manipulation. This report presents a case of a young female who presented with bilateral vertebral artery dissection post-chiropractic manipulation. The incidence and clinical outcomes of vertebral artery dissection, and the pathophysiology and clinical findings present in lateral medullary syndrome, will be discussed.

\section{CASE REPORT}

A 25-year-old female presented to the emergency department in October 2011 with occipital headache of four-week duration and new onset dizziness, paresthesia, dysphagia, and 'pulling to the left', which developed whilst jogging that morning. History revealed visits to a chiropractor with posterior headache and neck pain, four weeks and one week prior to this presentation. 
Cervical manipulation was performed on both occasions. Worsening left occipital and cervical pain developed following the second visit, with associated nausea and vomiting.

Neurological examination revealed an ataxic gait with falling to the left. Facial inspection revealed a left ptosis and miosis, consistent with partial left-sided Horner's syndrome. Nystagmus was present with rapid horizontal phase towards the right. Left-sided facial weakness and bulbar involvement was evident with a flattened left nasolabial fold, decreased left palatal movement, and uvula deviation to the right. Decreased pin-prick sensation and loss of temperature discrimination was detected over the left maxilla and throughout the right upper and lower limbs. Posterior columns were intact.

Left-sided cranial nerve signs, ipsilateral Horner's syndrome, and contralateral spinothalamic involvement suggested lateral medullary syndrome. A provisional diagnosis of a left medullary lesion secondary to vertebral artery dissection was made given the lack of typical stroke risk factors and the history of recent spinal manipulation. Differentials included embolic phenomena and tumor given the patient's age.

Magnetic resonance imaging (MRI) scan revealed a DWI-enhancing lesion in the left lateral medulla (Figure 1). Subsequent magnetic resonance angiography (MRA) was suspicious for left vertebral artery dissection. A follow-up MRI scan at 4th-week post-incident revealed a new, asymptomatic, lesion in the right cerebellum. Repeat MRA (Figure 2A) and CTA (Figure 2B) of the

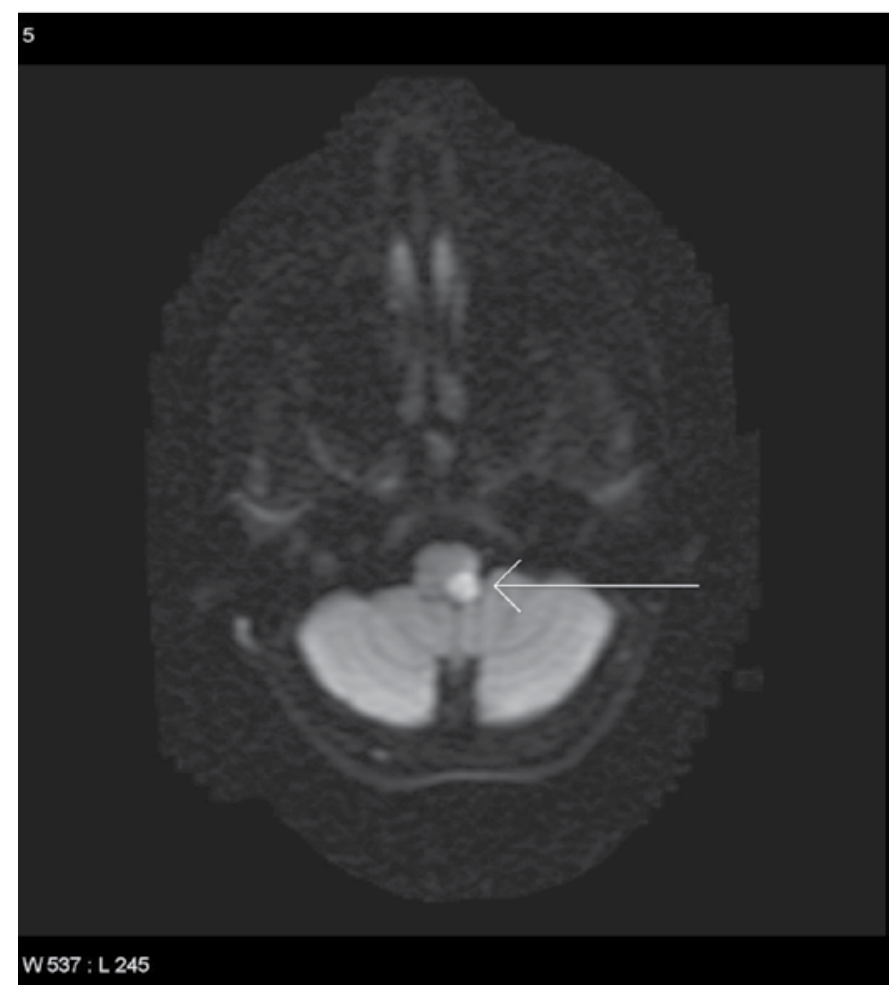

Figure 1: Left lateral medullary infarct caused by bilateral vertebral artery dissection. Diffusion weighted image on mangetic resonance imaging demonstrates a rounded focus of restricted diffusion consistent with a left lateral medullary infarct (arrow). vertebral arteries revealed bilateral vertebral artery dissection with bilateral posterior inferior cerebellar artery (PICA) territory infarcts. The patient was managed conservatively with aspirin and atorvastatin, progressing well with rehabilitation.
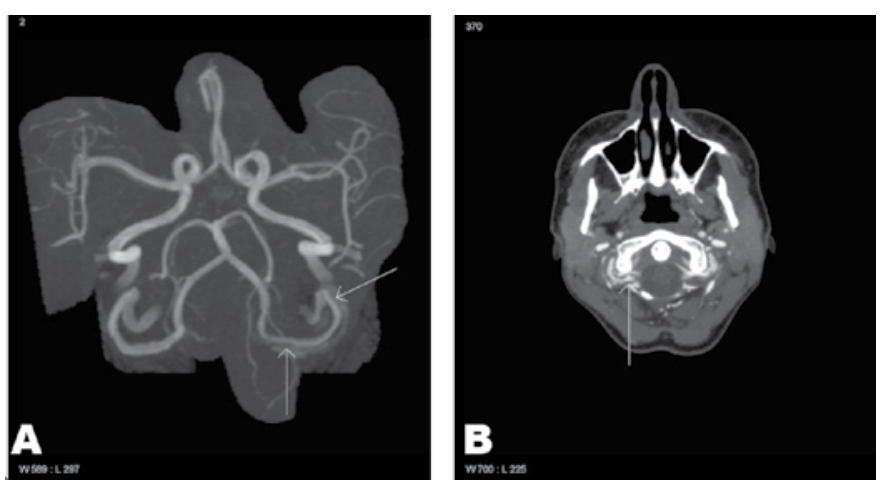

Figure 2: (A) Magnetic resonance imaging demonstrates bilateral vertebral arteryirregular luminal narrowing consistent with bilateral vertebral artery dissection. This is more easily appreciated on the left (arrows). (B) Computed tomography angiogram of neck demonstrating irregular luminal narrowing and a focal dilatation of the right vertebral artery consistent with vertebral artery dissection and a dissecting aneurysm (arrow). Left vertebral artery dissection also present.

\section{DISCUSSION}

Lateral medullary syndrome (or Wallenberg syndrome) is a recognised complication of posterior circulation infarction, usually the result of ipsilateral vertebral artery or PICA occlusion [1]. Clinical features are related to vestibulocerebellar, sensory, bulbar and autonomic nuclei involvement (Table 1). Spinothalamic tract involvement leads to impaired pain and temperature sensation over the contralateral side of the body (due to fiber decussation in the spinal cord), while Horner's

Table 1: Features of lateral medullary syndrome [2].

\begin{tabular}{|c|c|c|}
\hline $\begin{array}{l}\text { General } \\
\text { Symptoms }\end{array}$ & Ipsilateral Signs & $\begin{array}{l}\text { Contralateral } \\
\text { Signs }\end{array}$ \\
\hline $\begin{array}{l}\text { Dizziness * } \\
\text { Vertigo } \\
\text { Falling / veering } \\
\text { to one side } \\
\text { (ipsilateral)* } \\
\text { Difficulty sitting } \\
\text { upright without } \\
\text { support } \\
\text { Dysphagia * } \\
\text { Diplopia * }\end{array}$ & $\begin{array}{l}\text { Loss of pain and } \\
\text { temperature } \\
\text { sensation in face* } \\
\text { Horner's syndrome } \\
\text { (ptosis, miosis, } \\
\text { anhydrosis) } \\
\text { Paralysis of palate* } \\
\text { Laryngeal and } \\
\text { pharyngeal paralysis } \\
\text { Nystagmus } \\
\text { (rotational } \\
\text { component) }\end{array}$ & $\begin{array}{l}\text { Loss of pain and } \\
\text { temperature } \\
\text { sensation in trunk } \\
\text { and limbs * } \\
\text { Uvula deviation * } \\
\text { Nystagmus (rapid } \\
\text { horizontal phase) * }\end{array}$ \\
\hline
\end{tabular}


syndrome (ipsilateral ptosis and miosis) is related to descending sympathetic tract impairment [1].

Cervical artery dissection (internal carotid or vertebral artery dissection (VAD) has an annual incidence of 2.63.0 per 100,000 people [2]. It is the primary cause of $2 \%$ of ischemic strokes but accounts for 10-25\% in young adults [2].

There have been case reports associating chiropractic manipulation with unilateral and bilateral VAD and epidemiological links have been established [3, 4]. Spinal manipulation therapy is an independent risk factor for $\mathrm{VAD}$ and accelerates embolization in existing lesions [4]. The vertebral artery is particularly susceptible to cervical manipulation due to its mobility within the vertebral foramina, its proximity to the vertebral bodies, and its sharp directional change [3].

The aim of early diagnosis and treatment of VAD is to prevent progression to ischemic stroke and other thrombotic complications. Currently, there are no published multi-cohort trials evaluating anti-coagulation versus anti-platelet agents for treatment of VAD. A recent meta-analysis for internal carotid artery dissection revealed no significant difference in outcome between anticoagulants and anti-platelets [5]. Prognosis is usually favorable for $\mathrm{VAD}$, with low recurrence rates, good functional recovery and high rates of recanalization [3].

\section{CONCLUSION}

Chiropractic spinal manipulation is a recognised cause of vertebral artery dissection (VAD) presenting symptoms may vary from ipsilateral occipital headache to signs of cerebral ischemia such as lateral medullary syndrome. Patients presenting with headache and focal neurology following spinal manipulation should be managed with a high index of suspicion.

\section{Acknowledgements}

Special thanks to Dr Jane Hoare (Specialist Physician and Director of Medicine - Ipswich Hospital), Dr Johannes Moolman (Cardiologist - Ipswich Hospital) and Dr Benjamin Ong (Diagnostic Radiologist - Princess Alexandra Hospital).

\section{Author Contributions}

Matthew Kynan Burrage - Substantial contributions to conception and design, Acquisition of data, Analysis and interpretation of data, Drafting the article, Revising it critically for important intellectual content, Final approval of the version to be published

Clare Therese Costello - Analysis and interpretation of data, Drafting the article, Revising it critically for important intellectual content, Final approval of the version to be published

\section{Guarantor}

The corresponding author is the guarantor of submission.

\section{Conflict of Interest}

Authors declare no conflict of interest.

\section{Copyright}

(C) Matthew Kynan Burrage et al. 2014; This article is distributed under the terms of Creative Commons attribution 3.0 License which permits unrestricted use, distribution and reproduction in any means provided the original authors and original publisher are properly credited. (Please see www.ijcasereportsandimages.com/ copyright-policy.php for more information.)

\section{REFERENCES}

1. Smith W, English J, Claiborne Johnstone S. Cerebrovascular Diseases. In: Longo D, Fauci S, Kasper D, Hauser S, Jameson J, Loscalzo J, editors. Harrison's Principles of Internal Medicine. 18th ed. Sydney. McGraw-Hill 2012.

2. Savitz SI, Caplan LR. Vertebrobasilar disease. New England Journal of Medicine 2005;352(25):2618-6.

3. Kim YK, Schulman S. Cervical artery dissection: Pathology, epidemiology and management. Thrombosis Research 2009;123(6):810-21.

4. Smith WS, Johnston SC, Skalabrin EJ, et al. Spinal Manipulative therapy is an independent risk factor for vertebral artery dissection. Neurology 2003;60(9):1424-8.

5. Lyrer P, Engelter S. Antithrombotic drugs for carotid artery dissection. Cochrane Database Syst Rev 2010;6(10):CDoo0255. 


\section{ABOUT THE AUTHORS}

Article citation: Burrage MK, Costello CT. Lateral medullary syndrome post-chiropractic manipulation in a 25year old female with headache. International Journal of Case Reports and Images 2014;5(4):295-298.

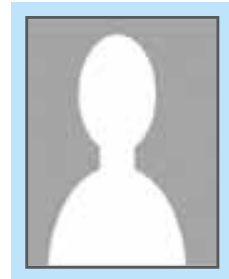

Matthew Burrage is a Medical Registrar undergoing basic physician training at the Princess Alexandra Hospital in Brisbane, Australia. He has a strong interest in Cardiology.

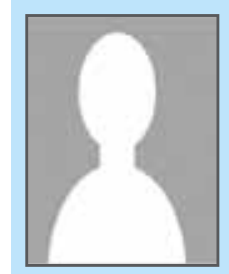

Clare Costello is a Medical Registrar undergoing basic physician training at the Mater Adults Hospital in Brisbane Australia. She has a broad interest in General medicine.

Access full text article on other devices

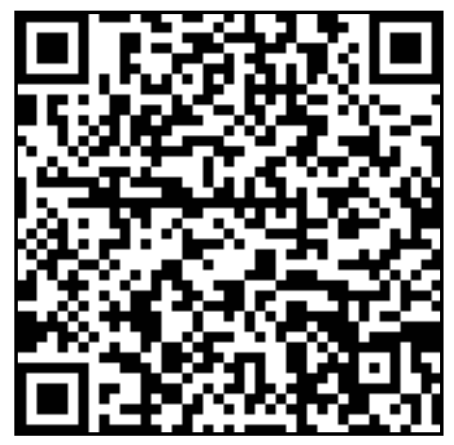

Access PDF of article on other devices

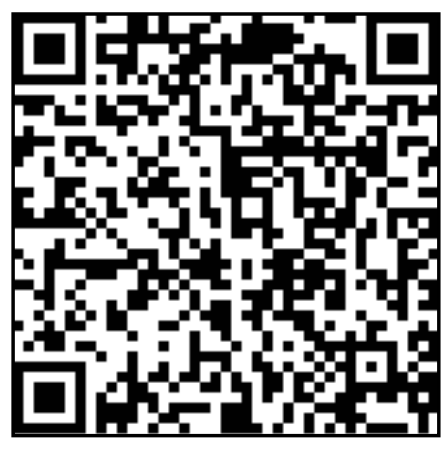

